\title{
Increasing Inflorescence Dry Weight and Cannabinoid Content in Medical Cannabis Using Controlled Drought Stress
}

\author{
Deron Caplan', Mike Dixon, and Youbin Zheng ${ }^{2}$ \\ School of Environmental Sciences, University of Guelph, Guelph, Ontario, \\ N1G 2W1, Canada
}

Additional index words. Cannabis sativa, marijuana, deficit irrigation, plant water potential, medicinal crops, volumetric soil moisture content

\begin{abstract}
Controlled application of drought can increase secondary metabolite concentrations in some essential oil-producing crops. To evaluate the effects of drought on cannabis (Cannabis sativa $\mathrm{L}$.) inflorescence dry weight and cannabinoid content, drought stress was applied to container-grown cannabis plants through gradual growing substrate drying under controlled environment. Fertigation was withheld during week 7 in the flowering stage until midday plant water potential (WP) was approximately $-1.5 \mathrm{MPa}$ (drought stress threshold). This occurred after 11 days without fertigation. A well-irrigated control was used for comparison. Leaf net photosynthetic rate $\left(P_{n}\right)$, plant WP, wilting (leaf angle), and volumetric moisture content (VMC) were monitored throughout the drying period until the day after the drought group was fertigated. At the drought stress threshold, $P_{n}$ was $42 \%$ lower and plant $W P$ was $50 \%$ lower in the drought group than the control. Upon harvest, drought-stressed plants had increased concentrations of major cannabinoids tetrahydrocannabinol acid (THCA) and cannabidiolic acid (CBDA) by $12 \%$ and $13 \%$, respectively, compared with the control. Further, yield per unit growing area of THCA was $43 \%$ higher than the control, CBDA yield was $47 \%$ higher, $\Delta^{9}$-tetrahydrocannabinol (THC) yield was $50 \%$ higher, and cannabidiol (CBD) yield was $67 \%$ higher. Controlled drought stress may therefore be an effective horticultural management technique to maximize both inflorescence dry weight and cannabinoid yield in cannabis, although results may differ by cannabis cultivar or chemotype.
\end{abstract}

The historic prohibition of cannabis ( Cannabis sativa L.) has stunted scientific research on its production, leaving growers to rely on guides and online resources based heavily on anecdotal information. In the past decade, the regulations surrounding cannabis production and use, especially for medicinal purposes, have become increasingly liberalized in North America and in some parts of Europe (Chandra et al., 2017), allowing research in this field.

The essential oil of female cannabis inflorescences gives the crop its value as a medicinal and recreational product; these oils are concentrated mostly in glandular trichomes and contain a diverse array of secondary metabolites, including a class of meroterpenoid compounds known as

Received for publication 21 Aug. 2018. Accepted for publication 11 Mar. 2019.

We are grateful to VIVO Cannabis Inc (formerly ABcann Medicinals Inc.) for providing funding, as well as materials, expertise, and ground-level support. We also thank EZ-GRO Inc. for supplying materials. We thank Newton Tran, Jared Stoochnoff, and Jonathan Stemeroff for their vital technical support.

${ }^{1}$ Current address: The Flowr Group (Okanagan) Inc., Kelowna, British Columbia, V4V 1S5, Canada.

${ }^{2}$ Corresponding author. E-mail: yzheng@uoguelph.ca. phytocannabinoids (cannabinoids; Chandra et al., 2017; Potter, 2014). Some cannabinoids, including THC and CBD, have been widely studied for their psychoactive and medicinal properties (Elzinga et al., 2015; Mechoulam et al., 1970; Vemuri and Makriyannis, 2015), but the medicinal properties of other cannabinoids and cannabinoid interactions are still mostly unknown (McPartland and Russo, 2001; Russo, 2011). In live plants, cannabinoids exist largely as carboxylic acids such as THCA and CBDA (Muntendam et al., 2012). These acids decarboxylate during storage (Ross and ElSohly, 1997; Taschwer and Schmid, 2015) and upon heating (Kimura and Okamoto, 1970) to become neutral cannabinoids, such as THC and CBD.

The inflorescence dry weight and secondary metabolite content in cannabis is largely controlled through breeding and phenotype selection (Muntendam et al., 2012); however, horticultural management techniques such as fertilization (Bócsa et al., 1997; Caplan et al., $2017 \mathrm{a} ; 2017 \mathrm{~b}$ ), choice of growing substrate (Caplan et al., 2017a, 2017b), air temperature in the growing environment (Chandra et al., 2011; Latta and Eaton, 1975), horticultural lighting intensity and quality (Lydon et al., 1987; Potter and Duncombe, 2012), and photoperiod (Potter, 2009) also have a substantial impact. Further, controlled exposure to stress may be an effective method to increase the production of some secondary metabolites in cannabis. For example, treatment with ultraviolet $\mathrm{B}$ radiation, which is not used in photosynthesis, may increase THC concentration in cannabis inflorescences under controlled environment conditions (Lydon et al., 1987).

Drought stress is a major stimulator of secondary metabolites in plants. This is exemplified in herbs and spices cultivated in semiarid regions such as the Mediterranean. Intermittent drought and high levels of solar radiation in these areas have been attributed to aromatic herbs and spices with abundant essential oil (Kleinwächter and Selmar, 2015). In the literature, there are no reports on the effects of drought stress on cannabis secondary metabolism; however, secondary metabolite accumulation due to drought stress has been documented in a number of other herbaceous species (Baher et al., 2002; Bettaieb et al., 2009; Kleinwächter and Selmar, 2015). In summer savory (Satureja hortensis), plants that were highly drought stressed during the flowering stage had 31\% higher essential oil concentration than a well-watered control (Baher et al., 2002). Likewise, drought stress increased essential oil concentration in lemon balm (Melissa officinalis L.) and lemon catmint (Nepeta cataria L. $f$. citriodora) compared with a well-watered control but did not for sage (Salvia officinalis L.). Although concentrations were higher, essential oil yield (per unit growing area) of lemon catmint and lemon balm was lower in the drought-stressed plants because of reduced growth and harvestable plant material.

In contrast, both Bettaieb et al. (2009) and Nowak et al. (2010) have documented not just increased essential oil concentration in sage by up to four times, but also higher essential oil yield in droughtstressed plants compared with a nonstressed control. Other than the notable exceptions in sage, increased essential oil yield per unit growing area is rarely cited (Kleinwächter and Selmar, 2015), possibly because drought stress has well-documented negative impacts on plant growth and can reduce harvestable plant material. Drought reduces rates of carbon assimilation as a result of both stomatal and metabolic limitations (Chaves, 1991; Flexas et al., 2002; Tezara et al., 1999). To maximize essential oil or secondary metabolite yield, the level and timing of the drought stress should be such that dry weight losses are minimized (Nakawuka et al., 2014).

In applying drought stress over extended periods, researchers generally aim to maintain constant levels of root zone WP, either through use of a solute-infused substrate (Charles et al., 1990; Van Der Weele et al., 2000) or by regulating soil/growing-substrate moisture content (Baher et al., 2002; Blanch et al., 2009; Manukyan, 2011; Nowak et al., 2010). This allows for long-term assessment of the drought stress response; however, 
these methods involve a sustained level of drought rather than mimicking natural substrate saturation and drying cycles. Allowing the growing substrate to dry before irrigation increases the level of root zone oxygen, which can improve nutrient uptake and root growth and prevent root-borne disease (Caplan et al., 2017a; Jackson and Colmer, 2005; Zheng et al., 2007). Substratedrying techniques that incorporate a wetting and drying cycle are preferred to observe both the immediate effects of the stressor as well as subsequent acclimation. This technique requires the use of a growing substrate that can effectively re-saturate after an extended dry period. Peat-based substrates without incorporated wetting agents, for example, may not be effective (Fields et al., 2014).

Drought stress timing is also essential to minimize dry weight losses and maximize essential oil yield and the concentration of secondary metabolites; differences in growth stage and natural timing of phytochemical accumulation must be considered by species (Petropoulos et al., 2004). The cannabis life cycle includes two growth stages, vegetative and flowering, which are controlled by photoperiod. A short-day photoperiod $(\approx 12 \mathrm{~h})$ triggers flowering that may last $\approx 7$ to 12 weeks depending on cultivar and growing conditions (Potter, 2014). Cannabinoids accumulate mostly during the flowering stage, but the timing of peak cannabinoid concentration varies by chemotype and cultivar. Drug-type varieties of chemotype I have a high THCA:CBDA ratio $(>1.0)$, whereas varieties of chemotype II have an intermediate ratio (generally 0.5-2.0) (Pacifico et al., 2008). For chemotype I, peak THCA concentration is approximately week 9 of the flowering stage, and for chemotype II, the peak is approximately week 7. Peak CBDA in chemotype I is approximately week 11 of the flowering stage; in chemotype II, it varies minimally from week 8 onward (Aizpurua-Olaizola et al., 2016; Muntendam et al., 2012).

In the present study, drought stress was applied to a chemovar II cultivar during week 7 of the flowering stage. It was hypothesized that controlled drought stress may be a valuable tool for growers to improve the quality of their cannabis crops. The objective was to evaluate the effects of drought stress on inflorescence dry weight and cannabinoid content and yield in cannabis.

\section{Materials and Methods}

\section{Plant culture}

Fourteen-day-old vegetatively propagated rooted cuttings $(\approx 10 \mathrm{~cm}$ high with $\approx 6$ leaves) of Cannabis sativa L. 'NC:Med (Nebula)' were transplanted into round blow-molded black pots $(102 \mathrm{~mm}$ diameter $\times 89 \mathrm{~mm}$ height) containing a customblended organic growing substrate $[40 \%$ to $45 \%$ ( vol/vol) sphagnum peatmoss, $20 \%$ to $25 \%$ chunk coconut coir, $20 \%$ to $25 \%$ horticultural grade perlite and $5 \%$ to $10 \%$ worm casings; Premier Tech Horticulture, Rivière-du-Loup, QC, Canada] with one plant per pot. Cuttings were taken from the same stock plant and were therefore genetically identical. Pots were placed in a walk-in growth chamber $\left(15 \mathrm{~m}^{2}\right)$ at a density of 97 plants $/ \mathrm{m}^{2}$. Growth chamber environmental parameters are presented in Table 1.

Plants were hand-fertigated, as per Caplan et al. (2017b), using Nutri Plus Organic Grow liquid organic fertilizer $(4.0 \mathrm{~N}-1.3 \mathrm{P}-$ 1.7K; EZ-GRO Inc., Kingston, ON, Canada) at a rate that supplied $389 \mathrm{mg}$ $\mathrm{N} / \mathrm{L}$ amended with $2 \mathrm{~mL} \cdot \mathrm{L}^{-1}$ of calciummagnesium supplement $(0.0 \mathrm{~N}-0.0 \mathrm{P}-0.0 \mathrm{~K}-$ $3.0 \mathrm{Ca}-1.6 \mathrm{Mg}$; EZ-GRO Inc.), diluted with reverse osmosis (RO) water and with a $20 \%$ leaching fraction. Other nutrient element concentrations of Nutri Plus Organic Grow were (in $\mathrm{mg} \cdot \mathrm{L}^{-1}$ ): $14.5 \mathrm{Zn}, 12.0 \mathrm{~B}, 2.6 \mathrm{Mo}$, $2.1 \mathrm{Cu}$, and $8.5 \mathrm{Fe}$. Fertigation was administered when mean substrate moisture was $\approx 30 \%$, measured using a WET-2 soil moisture sensor (Delta-T Devices Ltd., Cambridge, UK)

At $15 \mathrm{~d}$ after transplant (DAT), 8 plants with similar height and canopy size were selected and transferred into a larger walkin growth chamber $\left(130 \mathrm{~m}^{2}\right)$ for the flowering stage. This was considered the first day of the flowering stage (DFS). Plants were transplanted into 11-L blow-molded black pots $(279 \mathrm{~mm}$ diameter $\times 241 \mathrm{~mm}$ height $)$ containing Pro-Mix HP Mycorrhizae (Premier Tech Horticulture) and spaced on growing tables at a density of 6.4 plants $/ \mathrm{m}^{2}$. Trial plants were bordered on all sides by cannabis plants of the same age and of similar size.

During the first 10 DFS, plants were handfertigated at a rate that supplied $389 \mathrm{mg} \mathrm{N} / \mathrm{L}$ of Nutri Plus Organic Grow, as per Caplan et al. (2017b), whenever substrate moisture content reached $\approx 20 \%$. From then on, plants were fertigated as per Caplan et al. (2017a), using Nutri Plus Organic Bloom (2.00N$0.87 \mathrm{P}-3.32 \mathrm{~K}$; EZ-GRO Inc.) at a rate that supplied $170 \mathrm{mg} \mathrm{N} / \mathrm{L}$, diluted with $\mathrm{RO}$ water. Other nutrient element concentrations in Nutri Plus Organic Bloom were (in $\mathrm{mg} \cdot \mathrm{L}^{-1}$ ): $100 \mathrm{Mg}, 10.0 \mathrm{Zn}, 12.8 \mathrm{~B}, 0.1 \mathrm{Mo}$, $2.3 \mathrm{Cu}$, and $6.8 \mathrm{Fe}$. Flowering-stage fertigation solutions were also amended with 5 $\mathrm{mL} \cdot \mathrm{L}^{-1}$ of calcium-magnesium supplement $(0.0 \mathrm{~N}-0.0 \mathrm{P}-0.0 \mathrm{~K}-3.0 \mathrm{Ca}-1.6 \mathrm{Mg} ; \mathrm{EZ}-\mathrm{GRO}$ Inc.) and with Organa ADD micronutrient supplement, at a rate that supplied $22.9 \mathrm{mg}$ $\mathrm{N} / \mathrm{L} \quad(2.0 \mathrm{~N}-0.0 \mathrm{P}-0.0 \mathrm{~K} ; \quad$ EZ-GRO Inc.). Other nutrient element concentrations in Organa ADD were (in $\mathrm{mg} \cdot \mathrm{L}^{-1}$ ): $100.0 \mathrm{Ca}$, 29851 Zn, 4892 Mn, 1239 B, 12.7 Mo, 2419 $\mathrm{Cu}$, and $2917 \mathrm{Fe}$. Fertigation solution $\mathrm{pH}$ was adjusted to maintain substrate $\mathrm{pH}$ between 5.5 and 6.3, measured using a soil $\mathrm{pH}$ probe (Hanna HI 99121; Hanna Instruments, Woonsocket, RI).

\section{Treatments}

At 39 DFS, plants were randomly assigned to drought or control treatment groups, with 4 plants in each group. Each potted plant was an experimental unit. The control was irrigated as previously described for the flowering stage, with a fertigation event triggered when the substrate moisture content of an individual plant reached $\approx 20 \%$. Fertigation was withheld from drought treatment until plant WP reached between -1.4 and $-1.5 \mathrm{MPa}$.

\section{Drought stress indicators}

Plant water potential. Stem psychrometers and data loggers (PSY1; ICT International Pty Ltd., Armidale, NSW, Australia) were installed on each plant, and plant WP measurements were taken every 15 -minutes. The procedures outlined by Tran et al. (2015) were followed to install and maintain the psychrometers. Plant WP was noted immediately before fertigating the drought group and daily, at midday up until $1 \mathrm{~d}$ after the fertigation. Psychrometer reinstallations were necessary if plant WP readings suddenly dropped to zero or were positive while lights were on. These circumstances usually indicated that the vapor seal between the psychrometer and the stem was broken, condensation had accumulated inside the chamber, or the thermocouple was damaged (Stoochnoff et al., 2018).

Substrate moisture content. Capacitancetype substrate moisture sensors $\left(\mathrm{ECH}_{2} \mathrm{O}-\mathrm{TE}\right.$; Decagon Devices Inc., Pullman, WA) were inserted vertically into the substrate surface of each pot and connected to two fiveport data loggers (EM50; Decagon Devices Inc.). The moisture sensors measured dielectric permittivity every $15 \mathrm{~min}$, which was converted to volumetric moisture content (VMC) using a substrate-specific calibration. To ensure that the substrate in the drought treatment adequately rehydrated after fertigation, VMC at midday the day after fertigation of the drought group was compared with that of the control, measured at an equal interval after the control plants were last irrigated.

Leaf net photosynthetic rate. Leaf net photosynthetic rate $\left(\mathrm{P}_{\mathrm{n}}\right)$ was measured each day between 8 and $9 \mathrm{~h}$ into the light cycle beginning at 39 DFS as well as immediately before fertigating the drought group. Measurements were made using a portable photosynthesis measurement system (LI6400XT; LI-COR Biosciences, Lincoln, $\mathrm{NE}$ ) on the youngest fully expanded leaf (center leaflet $>10 \mathrm{~cm}$ ). Light was supplied by $6400-02 \mathrm{~B}$ red-blue light-emitting diodes (LI-COR) with photosynthetically active radiation set to around chamber canopy level $\left(450 \mu \mathrm{mol} \cdot \mathrm{m}^{-2} \cdot \mathrm{s}^{-1}\right) . \mathrm{CO}_{2}$ concentration in the leaf cuvette was maintained at $800 \mu \mathrm{mol} \cdot \mathrm{mol}^{-1}$, and block temperature was maintained at $20^{\circ} \mathrm{C}$.

Relative leaf angle. Initial leaf angle was measured at midday at treatment initiation using a handheld pivoting angle-finder and a protractor. Subsequent leaf angle measurements were taken when wilting was first evident then, three to four times a day after that until fertigation of the drought group. 


\begin{tabular}{|c|c|c|c|c|}
\hline & \multicolumn{4}{|c|}{ Days after transplant } \\
\hline \multirow{4}{*}{$\begin{array}{l}P A R^{z}\left(\mu \mathrm{mol} \cdot \mathrm{m}^{-2} \cdot \mathrm{s}^{-1}\right) \\
\text { Air temperature }\left({ }^{\circ} \mathrm{C}\right) \\
\text { Relative humidity }(\%) \\
\mathrm{CO}_{2} \text { concentration }(\mathrm{ppm})\end{array}$} & $100 \pm 1.3^{y}$ & $200 \pm 1.9$ & $300 \pm 2.6$ & $400 \pm 4.1$ \\
\hline & \multicolumn{4}{|c|}{ 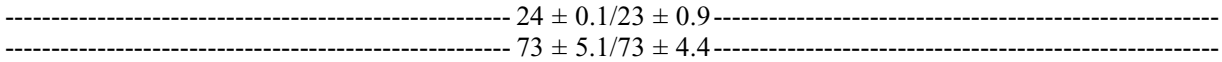 } \\
\hline & \multicolumn{4}{|c|}{ } \\
\hline & \multicolumn{4}{|c|}{ Days in the flowering stage } \\
\hline$P A R^{\mathrm{x}}\left(\mu \mathrm{mol} \cdot \mathrm{m}^{-2} \cdot \mathrm{s}^{-1}\right)$ & \multirow{2}{*}{\multicolumn{2}{|c|}{--- }} & \multicolumn{2}{|c|}{ - } \\
\hline Air temperature $\left({ }^{\circ} \mathrm{C}\right)$ & & & -------------------20 & 0.7 -------------- \\
\hline Relative humidity (\%) & $70 \pm 0.4 / 70 \pm 0.5$ & $65 \pm 0.7 / 65 \pm 0.3$ & $60 \pm 0.9 / 61 \pm 1.2$ & $55 \pm 1.4 / 60 \pm 1.4$ \\
\hline
\end{tabular}

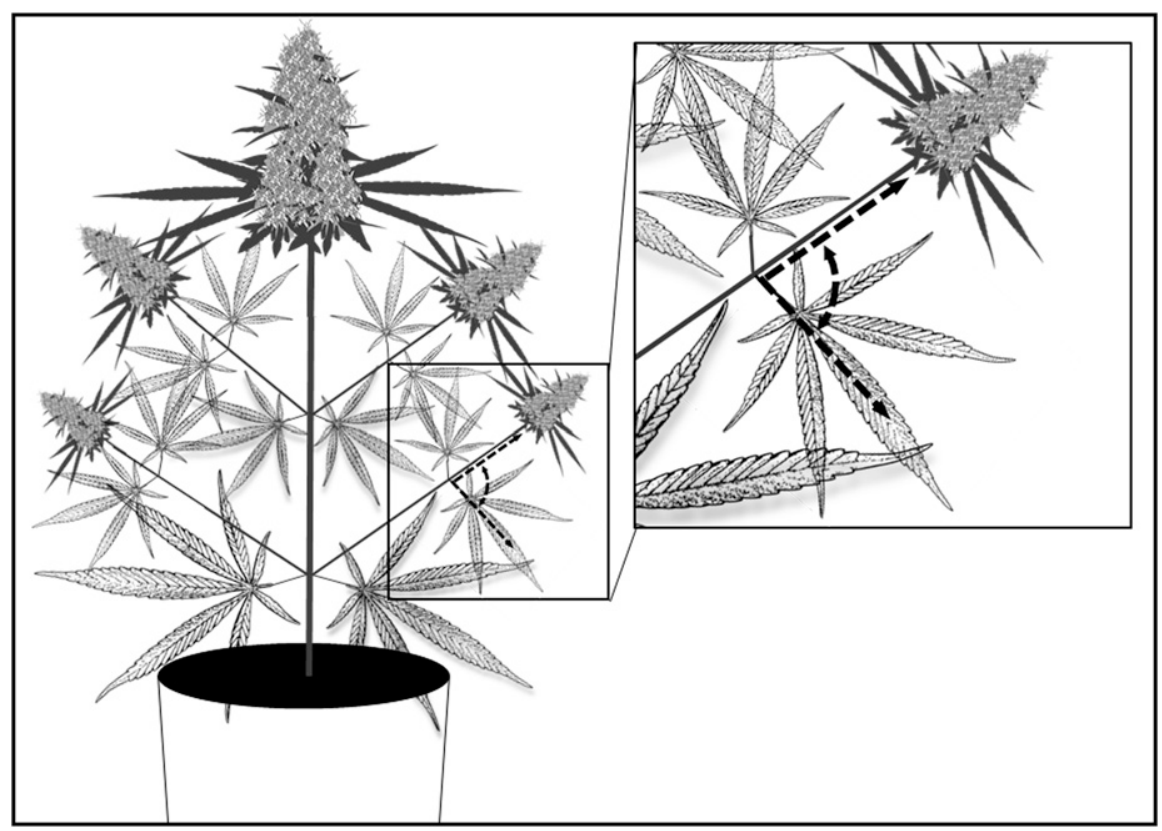

Fig. 1. Location for leaf angle measurement to indicate the degree of wilting in cannabis.

New, fully expanded leaves on a side-branch from the first internode were selected for measurement, and petioles were marked with colored tape for future measurement (Fig. 1). The angle between the center of the middle leaflet and the stem from which it originates was measured. The leaflet tips were not used as reference points because "tip curl" is common in cannabis, sometimes related to a nutrient disorder. As leaves wilted, increasing leaf angle relative to the initial angle was noted.

Inflorescence dry weight and cannabinoid measurements. Plants were harvested at 54 DFS. Stems were cut at substrate level; large leaves were removed from stems, and plants were hung to dry at $18{ }^{\circ} \mathrm{C}\left(\mathrm{SD} \pm 0.1^{\circ} \mathrm{C}\right)$ and $45 \% \mathrm{RH}(\mathrm{SD} \pm 1.9 \%)$ for $2 \mathrm{~d}$ then cured at $18^{\circ} \mathrm{C}\left(\mathrm{SD} \pm 0.1{ }^{\circ} \mathrm{C}\right)$ and $57 \% \mathrm{RH}(\mathrm{SD} \pm 4.3 \%)$ for $12 \mathrm{~d}$. Inflorescences were then cut from branches (both shoot apex and axillary branches), and leaves that were protruding from the inflorescences were trimmed using a
Twister T4 mechanical trimming machine (Keirton Inc., Surrey, BC, Canada) before inflorescence dry weight measurement.

The dried, cured apical inflorescences of three plants from each group was stored under dark and cool conditions according to United Nations Office on Drugs and Crime (2009) before being analyzed by an independent laboratory (RPC Science and Engineering, Fredericton, NB, Canada). Analysis of the neutral cannabinoids THC, $\mathrm{CBD}$, cannabinol (CBN), cannabichromene $(\mathrm{CBC})$, and cannabigerol (CBG), as well as acid forms THCA, CBDA, and cannabigerolic acid (CBGA), were conducted by high-performance liquid chromatography as described in section 5.4.8 of United Nations Office on Drugs and Crime (2009). Moisture content of the dry inflorescence was determined using the methods described in the U.S. Pharmacopeial Convention, section 921, method 3 (U.S. Pharmacopeia and National Formulary, 2017) and cannabinoid concentration was corrected to zero percent moisture content. Cannabinoid yield was calculated as cannabinoid concentration multiplied by inflorescence dry weight, expressed per unit area $\left(\mathrm{g} \cdot \mathrm{m}^{-2}\right)$ and corrected to $0 \%$ moisture content.

\section{Statistical analysis}

Data were analyzed using JMP Statistical Discovery Version 13.0 (SAS Institute Inc., Cary, NC) at a type 1 error rate of $\leq 0.05$. Differences among means were tested using Student's $t$ test. If cannabinoid concentrations were below the detection limit $(<0.05 \%)$, the values were excluded from the analysis. The residuals of the preceding analyses were tested for normality and equality of variance using The Shapiro-Wilk's and Bartlett's tests, respectively.

\section{Results}

\section{Drought stress indicators}

During the 54-day flowering period, there were no symptoms of nutrient disorder and no observable differences in plant appearance between control and drought groups until the drought treatment was without fertigation for $\approx 9 \mathrm{~d}$. From $9 \mathrm{~d}$ without fertigation to harvest, plants under drought treatment showed signs of veinal chlorosis on older leaves and, to a lesser extent, newly formed leaves on the entire plant. Wilting was observed after $11 \mathrm{~d}$ without fertigation when leaf angle in the drought treatment was $52 \% \pm 0.7$ higher than the initially measured angles.

Up until $11 \mathrm{~d}$ without fertigation in the drought treatment, plant WP did not differ from the control groups $(P=0.78 ; \mathrm{n}=4$ for day 10$)$. Immediately before fertigating the drought group, on the 11th day without fertigation, plant WP in the drought treatment was $50 \%$ lower than in the control (Table 2). The day after fertigating plants in the drought treatment, their mean midday plant WP recovered to the same level as the control.

There were also notable differences in net photosynthetic rate $\left(\mathrm{P}_{\mathrm{n}}\right)$ and substrate 
volumetric moisture content (VMC) between drought and control treatments around the time of fertigating the drought group (Table 2). Immediately before fertigation, $\mathrm{P}_{\mathrm{n}}$ in the drought-stressed plants was $42 \%$ lower than the control, and VMC was $84 \%$ lower than the control. On the day after fertigation of the drought group at midday, $\mathrm{P}_{\mathrm{n}}$ partially recovered in the drought-stressed plants but was still 32\% lower than the control. Further, VMC in the drought group on the day after fertigation did not differ from that of the control as measured the day after it was last irrigated during this period.

\section{Inflorescence dry weight and cannabinoids}

Inflorescence dry weight in the control was $178 \pm 9.4 \mathrm{~g} \cdot \mathrm{m}^{-2}$ and was $232 \pm 18.5 \mathrm{~g} \cdot \mathrm{m}^{-2}$ in the drought treatment, but inflorescence dry weight did not differ statistically between the two treatments $(P=0.06 ; \mathrm{n}=3)$. The moisture content of the dried and cured inflorescences was $8 \pm 0.1 \%$ in the control, $11 \%$ lower than that in the drought treatment, at $9 \pm 0.1 \%(P=0.01 ; \mathrm{n}=3)$. Henceforward, the inflorescence dry weight and cannabinoid contents are corrected to $0 \%$ moisture.

Of the analyzed cannabinoids, all were detected in at least one sample, these included THC, THCA, CBD, CBDA, CBG, CBGA, and CBN. In the drought treatment, only one sample had a detectable concentration of $\mathrm{CBG}$ and $\mathrm{CBN}$, and in the control, there were no samples with detectable $\mathrm{CBN}$; therefore, comparisons could not be made for these cannabinoids, and the means for CBN were not presented.

The drought treatment elicited a $12 \%$ increase in THCA concentration and a 13\% increase in CBDA concentration but had no effect on the concentrations of the other detected cannabinoids (Table 3, top). Drought had substantial effects on cannabinoid yield, expressed as grams of cannabinoid from inflorescences per unit growing area $\left(\mathrm{g} \cdot \mathrm{m}^{-2}\right)$. In the drought treatment, THC yield was 50\% higher, THCA yield was $43 \%$ higher, CBD yield was $67 \%$ higher, and CBDA yield was $47 \%$ higher than in the control (Table 3, bottom).

\section{Discussion}

The controlled drought treatment substantially increased the concentrations of both major cannabinoids, THCA and CBDA, as well as yield of THCA, CBDA, THC, and CBD compared with the control. These results suggested that the level of drought stress applied was adequate to stimulate cannabinoid production without reducing inflorescence dry weight for this cultivar.

Plant WP proved to be an effective indicator of drought stress; at wilting point, there was a significant difference in plant WP between drought and control groups. The stem psychrometer is a useful tool for nondestructive assessment of plant-environment interactions that may vary by species and between individual plants (Dixon and Tyree, 1984). Traits such as crown architecture, root structure, and leaf morphology all affect water transport (Ali, 2010) and therefore drought responses. The combined effect of these and environmental parameters can be quantified through plant WP measurements (Dixon and Tyree, 1984; Stoochnoff et al., 2018). The use of stem psychrometers for irrigation scheduling is, however, not commercially viable. The sensors are costly and require significant technical training. Substrate VMC or leaf wilting are easier to measure and can be useful indicators of drought if correlated to plant WP data. Leaf angle measurements can be made in seconds using a protractor and/or angle finder; substrate VMC measurement generally requires several substrate moisture sensors, but data can be collected remotely (Bogena et al., 2007).

In the present study, leaf wilting was an effective indicator of plant stress. At the irrigation threshold for the drought treatment, plants were visibly wilted, and the indicator leaf angle increased by $\approx 50 \%$ from the turgid leaf angle. Using wilting as a drought-stress indicator may therefore be an effective method in cannabis production, particularly because it is easily measured. In potato (Solanum tuberosum L.), for example, leaf wilting may be the most obvious visual indicator of drought stress (Banik et al., 2016). Notably, wilting response to drought may vary by species (Xu et al., 2010) and can depend on the degree to which an individual plant is acclimated to drought stress (Banik et al., 2016; Flexas et al., 2009); therefore, using a 50\% increase in leaf angle wilting threshold as a drought stress indicator may be most effective if used with similar varieties of cannabis (chemovar II) and under similar environmental conditions (Table 1) to the present study.

To our knowledge, this was the first evaluation of the effects of controlled drought stress on cannabis; although, as previously described, drought can increase essential oil yield in some herbaceous crops. In droughtstressed sage, essential oil and monoterpene yield can increase up to $281 \%$ (Bettaieb et al., 2009) and 20\% (Nowak et al., 2010), respectively, over a well-watered control. Likewise, in

Table 2. Plant water potential, leaf net photosynthetic rate, and substrate moisture of cannabis under drought conditions and after subsequent fertigation at 7 weeks in the flowering stage.

\begin{tabular}{|c|c|c|c|c|}
\hline & Treatment & Plant water potential $(\mathrm{MPa})$ & $\begin{array}{l}\text { Net photosynthetic rate } \\
\left(\mu \mathrm{mol} \cdot \mathrm{m}^{-2} \cdot \mathrm{s}^{-1}\right)\end{array}$ & $\begin{array}{c}\text { Volumetric substrate moisture } \\
\text { content }(\%)\end{array}$ \\
\hline \multirow{3}{*}{$\begin{array}{l}\text { Immediately before fertigation } \\
\text { (wilting point) }\end{array}$} & Control & $-1.0 \pm 0.05^{z}$ & $13.2 \pm 1.14$ & $33.3 \pm 2.89$ \\
\hline & Drought & $-1.5 \pm 0.12$ & $7.7 \pm 0.80$ & $5.3 \pm 1.23$ \\
\hline & Significance ${ }^{\mathrm{y}}$ & $* *$ & $* *$ & $* * *$ \\
\hline \multirow[t]{3}{*}{ Midday after fertigation } & Control & $-0.9 \pm 0.09$ & $13.9 \pm 1.01$ & $43.2 \pm 1.36^{\mathrm{x}}$ \\
\hline & Drought & $-0.6 \pm 0.10$ & $9.4 \pm 0.65$ & $39.4 \pm 4.02$ \\
\hline & Significance & NS & $* *$ & NS \\
\hline
\end{tabular}

${ }^{\mathrm{z}}$ Data are means \pm SEM $; \mathrm{n}=3$ for volumetric moisture content of the control and $\mathrm{n}=4$ for all other means

$\mathrm{y}_{\mathrm{NS}}, *, * *, * * *$ Nonsignificant or significant at $P<0.05,0.01$, or 0.0001 , respectively.

${ }^{\mathrm{x}}$ Measured the day after the control was last irrigated during this period.

Table 3. Cannabinoid concentration and yield in the inflorescences of cannabis exposed to drought stress at week 7 in the flowering stage.

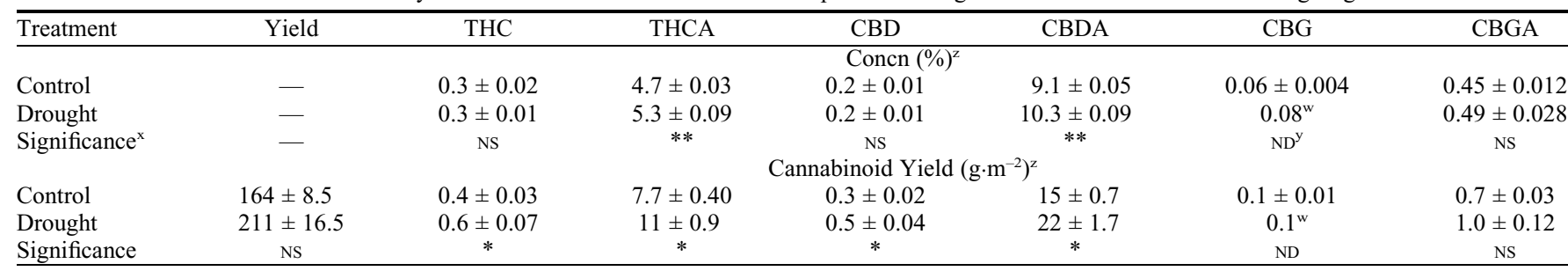

${ }_{\mathrm{z}}$ Data are means \pm SEM and are corrected to zero percent moisture content; $\mathrm{n}=3$ unless otherwise indicated.

$\mathrm{y}_{\mathrm{ND}}$, no data or insufficient data to compare means.

$\mathrm{xS}, *, * *, * * *$ Nonsignificant or significant at $P<0.05,0.01$, or 0.0001 , respectively.

${ }^{\mathrm{w}} \mathrm{n}=1$. 
curly-leafed parsley (Petroselinum crispum ssp. crispum L. cv. curly-leafed) grown under drought stressed conditions, plants were smaller but had higher oil concentrations than the wellwatered control. The density of the plants could therefore be increased to accommodate the decreased size and essential oil yield per unit area would be higher (Petropoulos et al., 2008).

Increases in secondary metabolite concentration due to drought stress usually coincides with reduced growth; however, this was not the case in the present study, at least in terms of inflorescence growth because there was no difference in inflorescence dry weight between drought and control groups. Secondary metabolites are formed from photosynthetic carbon (Peñuelas and Llusià, 2002), and drought can reduce $\mathrm{P}_{\mathrm{n}}$, as exemplified in the present study. In fact, it is common for $\mathrm{P}_{\mathrm{n}}$ of plants exposed to drought stress to recover only to $40 \%$ to $60 \%$ of their predrought levels on the day after irrigation, and $P_{n}$ may never fully recover (Delfine et al., 2005; Kirschbaum, 1987; Sofo et al., 2005). Nonetheless, in the present study, the yield of some cannabinoids increased irrespective of reduced carbon assimilation. Protective mechanisms help plants tolerate drought until some cumulative physiological threshold is exceeded, and only at this point is growth impeded (Ali, 2010; Xu et al., 2010). A period of drought insufficient to impede growth, such as in the present study, may be crucial to increasing secondary metabolite yield.

An understanding of the biochemical origins of cannabinoids and how they relate to other secondary metabolites may be useful to speculate how drought stress increased cannabinoid yield in the present study. For example, cannabinoids are closely related to some terpenoids that protect plants under stress. Cannabinoids and terpenoids share a similar biochemical pathway. Isopentenyl pyrophosphate is the basic building block of all terpenoids and is produced either in the cytosol and mitochondria through the Mevalonate pathway (Banthorpe et al., 1972) or in the plastids through the Mevalonate-independent (DXP) pathway (Eisenreich et al., 1998). The DXP pathway is the source of all mono, di-, and tetraterpenes, which include many essential oil components (Gershenzon et al., 2000). In cannabinoid synthesis, geranyl pyrophosphate (GPP) from the DXP pathway is combined with olivetolic acid (OA), a product of the polyketide pathway (Flores-Sanchez and Verpoorte, 2008; Hanuš et al., 2016), to produce cannabigerolic acid (CBGA) (Fellermeier et al., 2001). CBGA is then converted to more commonly known cannabinoids, such as THCA and CBDA, through various synthases (Taura et al., 1996).

Carotenoids and xanthophylls, which are also produced through the DXP pathway, are involved in mitigating photo-oxidative damage caused by environmental stress (Demmig-Adams, 1990). Stressors such as drought elicit the formation of reactive oxygen species in the chloroplasts, especially under high solar radiation (Penuelas et al., 2004). Production of antioxidant compounds in the chloroplasts such as carotenoids and the xanthophylls is upregulated in stressed plants to prevent cell damage (Eskling et al., 1997; MunnéBosch and Alegre, 2000). This may also be the case for other terpenes with antioxidant properties (Delfine et al., 2005; Llusià and Peñuelas, 1998; Munné-Bosch and Alegre, 2000). Environmental stressors that normally up-regulate terpenoid synthesis and accumulation may do the same for some cannabinoids because of their related biochemical origins.

Both water and fertilizer were applied together through fertigation, and thus there were likely differences in the amount of fertilizer applied to the treatment groups. The concentration of fertilizer in the irrigation water remained constant, and because the drought stress group was irrigated less than the control, it was also fertilized less. Nutrients are largely taken up through the roots along with water by mass transport, so it can be difficult to sustain adequate mineral nutrition uptake in dry substrates (Silber et al., 2003). This is a limitation in any method for long-term drought application. Nonetheless, research has shown that flowering-stage cannabis performs similarly under a range of organic fertigation rates (Caplan et al., 2017a), and in the present trial, the drought-stressed group had inflorescence dry weight similar to the control, which would not be expected if nutrition were lacking (Caplan et al., 2017a).

Repetition of drought stress and subsequent acclimation can influence the way in which plants respond to the stressor (Banik et al., 2016). The present study evaluated the effects of drought at a single point during the flowering stage, but timing of drought stress and drought-stress frequency could also affect secondary metabolism in cannabis. Some higher plants have the ability to acclimate to drought stress; stress resistance may increase after exposure to a low level of stress (Banik et al., 2016; Flexas et al., 2009). The acclimation responses from repeated drought stress could therefore further stimulate secondary metabolites in cannabis, although a longer drought event may be required to elicit the response in acclimated plants. More research is needed to evaluate the effects of drought-stress timing and acclimation on cannabis inflorescence dry weight and secondary metabolism. Lastly, because rates of cannabinoid accumulation vary by chemovar (Aizpurua-Olaizola et al., 2016; Muntendam et al., 2012), the effect of drought on other chemovars should be explored.

\section{Conclusions}

This study suggested that controlled drought stress can increase the concentration of the major cannabinoids THCA and CBDA and the yield of THCA, CBDA, THC, and $\mathrm{CBD}$ in chemovar II cannabis without reducing inflorescence dry weight and irrespective of decreased $P_{n}$. These results were achieved by gradually drying the substrate over $11 \mathrm{~d}$ until plant WP reached approxi- mately $-1.5 \mathrm{MPa}$ during week 7 in the flowering stage. Comparable results can be expected using leaf wilting as a drought-stress indicator with fertigation triggered at a leaf angle $50 \%$ higher than in its turgid state. This method for administering drought stress and the results of this study should be applicable for similar varieties of chemovar II cannabis; however, other chemovars or varieties may respond differently.

\section{Literature Cited}

Aizpurua-Olaizola, O., U. Soydaner, E. Öztürk, D. Schibano, Y. Simsir, P. Navarro, N. Etxebarria, and A. Usobiaga. 2016. Evolution of the cannabinoid and terpene content during the growth of Cannabis sativa plants from different chemotypes. J. Nat. Prod. 79:324-331.

Ali, M.H. 2010. Crop water requirement and irrigation scheduling. Fundamentals of irrigation an on farm water management: Volume 1. Springer, New York.

Baher, Z.F., M. Mirza, M. Ghorbanli, and M.B. Rezaii. 2002. The influence of water stress on plant height, herbal and essential oil yield and composition in Satureja hortensis L. Flavour Fragrance J. 17:275-277.

Banik, P., W. Zeng, H. Tai, B. Bizimungu, and K. Tanino. 2016. Effects of drought acclimation on drought stress resistance in potato (Solanum tuberosum L.) genotypes. Environ. Exp. Bot. 126:76-89.

Banthorpe, D.V., B.V. Charlwood, and M.J.O. Francis. 1972. The biosynthesis of monoterpenes. Chem. Rev. 72:115-155.

Bettaieb, I., N. Zakhama, W.A. Wannes, M.E. Kchouk, and B. Marzouk. 2009. Water deficit effects on Salvia officinalis fatty acids and essential oils composition. Scientia Hort. 120:271-275.

Blanch, J.S., J. Peñuelas, J. Sardans, and J. Llusià. 2009. Drought, warming and soil fertilization effects on leaf volatile terpene concentrations in Pinus halepensis and Quercus ilex. Acta Physiol. Plant. 31:207-218.

Bócsa, I., P. Máthé, and L. Hangyel. 1997. Effect of nitrogen on tetrahydrocannabinol (THC) content in hemp (Cannabis sativa L.) leaves at different positions. J. Intl. Hemp Assoc. 4:78-79.

Bogena, H.R., J.A. Huisman, C. Oberdörster, and H. Vereecken. 2007. Evaluation of a low-cost soil water content sensor for wireless network applications. J. Hydrol. 344:32-42.

Caplan, D., M. Dixon, and Y. Zheng. 2017a. Optimal rate of organic fertilizer during the flowering stage for cannabis grown in two coirbased substrates. HortScience 52:1796-1803.

Caplan, D., M. Dixon, and Y. Zheng. 2017b. Optimal rate of organic fertilizer during the vegetativestage for cannabis grown in two coir-based substrates. HortScience 52:1307-1312.

Chandra, S., H. Lata, M.A. Elsohly, L.A. Walker, and D. Potter. 2017. Cannabis cultivation: Methodological issues for obtaining medicalgrade product. Epilepsy Behav. 70:302-312.

Chandra, S., H. Lata, I.A. Khan, and M.A. Elsohly 2011. Temperature response of photosynthesis in different drug and fiber varieties of Cannabis sativa L. Physiol. Mol. Biol. Plants 17:297-303.

Charles, D.J., R.J. Joly, and J.E. Simon. 1990. Effects of osmotic stress on the essential oil content and composition of peppermint. Phytochemistry 29:2837-2840.

Chaves, M. 1991. Effects of water deficits on carbon assimilation. J. Expt. Bot. 42:1-16. 
Delfine, S., F. Loreto, P. Pinelli, R. Tognetti, and A. Alvino. 2005. Isoprenoids content and photosynthetic limitations in rosemary and spearmint plants under water stress. Agr. Ecosyst. Environ. 106:243-252.

Demmig-Adams, B. 1990. Carotenoids and photoprotection in plants: A role for the xanthophyll zeaxanthin. Biochim. Biophys. Acta Bioenerg. 1020:1-24.

Dixon, M.A. and M.T. Tyree. 1984. A new stem hygrometer, corrected for temperature gradients and calibrated against the pressure bomb. Plant Cell Environ. 7:693-697.

Eisenreich, W., M. Schwarz, A. Cartayrade, D. Arigoni, M.H. Zenk, and A. Bacher. 1998. The deoxyxylulose phosphate pathway of terpenoid biosynthesis in plants and microorganisms. Chem. Biol. 5:221-233.

Elzinga, S., J. Fischedick, R. Podkolinski, and J.C. Raber. 2015. Cannabinoids and terpenes as chemotaxonomic markers in cannabis. Nat. Prod. Chem. Res. 3:1-9.

Eskling, M., P.-O. Arvidsson, and H.-E. Akerlund. 1997. The xanthophyll cycle, its regulation and components. Physiol. Plant. 100:806-816.

Fellermeier, M., W. Eisenreich, A. Bacher, and M.H. Zenk. 2001. Biosynthesis of cannabinoids: Incorporation experiments with 13C-labeled glucoses. Eur. J. Biochem. 268:1596-1604.

Fields, J.S., W.C. Fonteno, and B.E. Jackson. 2014 Hydration efficiency of traditional and alternative greenhouse substrate components. HortScience 49:336-342.

Flexas, J., M. Barón, J. Bota, J.M. Ducruet, A. Gallé, J. Galmés, M. Jiménez, A. Pou, M. Ribas-Carbó, C. Sajnani, M. Tomàs, and $\mathrm{H}$. Medrano. 2009. Photosynthesis limitations during water stress acclimation and recovery in the drought-adapted Vitis hybrid Richter-110 (V. berlandieri $\times V$. rupestris). J. Expt. Bot. 60:2361-2377.

Flexas, J., J. Bota, J.M. Escalona, B. Sampol, and H. Medrano. 2002. Effects of drought on photosynthesis in grapevines under field conditions: An evaluation of stomatal and mesophyll limitations. Funct. Plant Biol. 29:461-471.

Flores-Sanchez, I.J. and R. Verpoorte. 2008. Secondary metabolism in cannabis. Phytochem. Rev. 7:615-639.

Gershenzon, J., M.E. McConkey, and R.B. Croteau. 2000. Regulation of monoterpene accumulation in leaves of peppermint. Plant Physiol. 122:205-214.

Hanuš, L.O., S.M. Meyer, E. Muñoz, O. TaglialatelaScafati, and G. Appendino. 2016. Phytocannabinoids: A unified critical inventory. Nat. Prod. Rep. 33:1357-1392.

Jackson, M.B. and T.D. Colmer. 2005. Response and adaptation by plants to flooding stress. Ann. Bot. 96:501-505.

Kimura, M. and K. Okamoto. 1970. Distribution of tetrahydrocannabinolic acid in fresh wild cannabis. Experientia 26:819-820.

Kirschbaum, M.U.F. 1987. Water stress in Eucalyptus pauciflora: Comparison of effects on stomatal conductance with effects on the mesophyll capacity for photosynthesis, and investigation of a possible involvement of photoinhibition. Planta 171:466-473.

Kleinwächter, M. and D. Selmar. 2015. New insights explain that drought stress enhances the quality of spice and medicinal plants: Potential applications. Agron. Sustain. Dev. 35:121-131.
Latta, R.P. and B.J. Eaton. 1975. Seasonal fluctuations in cannabinoid content of Kansas Marijuana. Econ. Bot. 29:153-163.

Llusià, J. and J. Peñuelas. 1998. Changes in terpene content and emission in potted Mediterranean woody plants under severe drought. Can. J. Bot. 76:1366-1373.

Lydon, J., A.H. Teramura, and C.B. Coffman. 1987. UV-B radiation effects on photosynthesis, growth and cannabinoid production of two Cannabis sativa chemotypes. Photochem. Photobiol. 46:201-206.

Manukyan, A. 2011. Effect of growing factors on productivity and quality of lemon catmint, lemon balm and sage under soilless greenhouse production: I. drought stress. Med. Aromat. Plant Sci. Biotechnol. 5:119-125.

McPartland, J.M. and E.B. Russo. 2001. Cannabis and cannabis extracts: Greater than the sum of their parts? J. Cannabis Ther. 1:103-132.

Mechoulam, R., A. Shani, H. Edery, and Y. Grunfeld. 1970. Chemical basis of hashish activity. Science 169:611-612.

Munné-Bosch, S. and L. Alegre. 2000. Changes in carotenoids, tocopherols and diterpenes during drought and recovery, and the biological significance of chlorophyll loss in Rosmarinus officinalis plants. Planta 210:925-931.

Muntendam, R., N. Happyana, T. Erkelens, F. Bruining, and O. Kayser. 2012. Time dependent metabolomics and transcriptional analysis of cannabinoid biosynthesis in Cannabis sativa var. Bedrobinol and Bediol grown under standardized condition and with genetic homogeneity. Online Intl. J. Med. Plants Res. 1:31-40.

Nakawuka, P., T.R. Peters, K.R. Gallardo, D. ToroGonzalez, R.O. Okwany, and D.B. Walsh. 2014. Effect of deficit irrigation on yield, quality, and costs of the production of native spearmint. J. Irrig. Drain. Eng. 140:05014002.

Nowak, M., M. Kleinwächter, R. Manderscheid, H.J. Weigel, and D. Selmar. 2010. Drought stress increases the accumulation of monoterpenes in sage (Salvia officinalis), an effect that is compensated by elevated carbon dioxide concentration. J. Appl. Bot. Food Qual. 83:133-136.

Pacifico, D., F. Miselli, A. Carboni, A. Moschella, and G. Mandolino. 2008. Time course of cannabinoid accumulation and chemotype development during the growth of Cannabis sativa L. Euphytica 160:231-240.

Peñuelas, J. and J. Llusià. 2002. Linking photorespiration, monoterpenes and thermotolerance in Quercus. New Phytol. 155:227-237.

Penuelas, J., S. Munné-Bosch, J. Llusià, and I. Filella. 2004. Leaf reflectance and photo- and antioxidant protection in Optical signals of oxidative stress? New Phytol. 162:115-124.

Petropoulos, S.A., D. Daferera, C.A. Akoumianakis, H.C. Passam, and M.G. Polissiou. 2004. The effect of sowing date and growth stage on the essential oil composition of three types of parsley (Petroselinum crispum). J. Sci. Food Agr. 84:1606-1610.

Petropoulos, S.A., D. Daferera, M.G. Polissiou, and H.C. Passam. 2008. The effect of water deficit stress on the growth, yield and composition of essential oils of parsley. Scientia Hort. 115:393-397.

Potter, D.J. 2009. The propagation, characterisation and optimisation of Cannabis sativa $\mathrm{L}$. as a phytopharmaceutical. King's College London, London, PhD Diss.

Potter, D.J. 2014. A review of the cultivation and processing of cannabis (Cannabis sativa L.) for production of prescription medicines in the UK. Drug Test. Anal. 6:31-38.

Potter, D.J. and P. Duncombe. 2012. The effect of electrical lighting power and irradiance on indoor-grown cannabis potency and yield. J. Forensic Sci. 57:618-622.

Ross, S.A. and M.A. ElSohly. 1997. CBN and $\Delta 9$ $\mathrm{THC}$ concentration ratio as an indicator of the age of stored marijuana samples. Bull. Narc. 49:139.

Russo, E.B. 2011. Taming THC: Potential cannabis synergy and phytocannabinoid-terpenoid entourage effects. Brit. J. Pharmacol. 163:13441364.

Silber, A., G. Xu, and R. Wallach. 2003. High irrigation frequency: The effects on uptake of nutrients, water and plant growth. Acta Hort. 627:89-96.

Sofo, A., A.C. Tuzio, B. Dichio, and C. Xiloyannis. 2005. Influence of water deficit and rewatering on the components of the ascorbate-glutathione cycle in four interspecific Prunus hybrids. Plant Sci. 169:403-412.

Stoochnoff, J.A., T. Graham, and M.A. Dixon. 2018. Drip irrigation scheduling for container grown trees based on plant water status. Irrig. Sci. 36:179-186.

Taschwer, M. and M.G. Schmid. 2015. Determination of the relative percentage distribution of THCA and $\triangle(9)-$ THC in herbal cannabis seized in Austria - Impact of different storage temperatures on stability. Forensic Sci. Intl. 254:167-171.

Taura, F., S. Morimoto, and Y. Shoyama. 1996. Purification and characterization of cannabidiolicacid synthase from Cannabis sativa L. Biochemical analysis of a novel enzyme that catalyzes the oxidocyclization of. J. Biol. Chem. 271:17411-17416.

Tezara, W., V.J. Mitchell, S.D. Driscoll, and D.W. Lawlor. 1999. Water stress inhibits plant photosynthesis by decreasing coupling factor and ATP. Nature 401:914-917.

Tran, N., P. Bam, K. Black, T. Graham, P. Zhang, M. Dixon, B. Reeves, and A. Downey. 2015. Improving irrigation scheduling protocols for nursery trees by relating cumulative water potential to concurrent vapour pressure deficit. Acta Hort. 1085:129-134.

United Nations Office on Drugs and Crime. 2009. Recommended methods for the identification and analysis of cannabis and cannabis products, manual for use by national drug analysis laboratories. Laboratory and Scientific Section, United Nations Office on Drugs and Crime, Vienna, Austria.

U.S. Pharmacopeia and National Formulary. 2017. USP 40-NF 35. U.S. Pharmacopeial, Rockville, MD

Vemuri, V.K. and A. Makriyannis. 2015. Medicinal chemistry of cannabinoids. Clin. Pharmacol. Ther. 97:553-558.

Van Der Weele, C.M., W.G. Spollen, R.E. Sharp, and T.I. Baskin. 2000. Growth of Arabidopsis thaliana seedlings under water deficit studied by control of water potential in nutrient-agar media. J. Expt. Bot. 51:1555-1562.

Xu, Z., G. Zhou, and H. Shimizu. 2010. Plant responses to drought and rewatering. Plant Signal. Behav. 5:649-654.

Zheng, Y., L. Wang, and M. Dixon. 2007. An upper limit for elevated root zone dissolved oxygen concentration for tomato. Scientia Hort. 113:162-165. 